\title{
METODOLOGIA DE PROJETOS: CAMINHOS PARA UMA PRÁTICA DOCENTE SOCIAL E EDUCACIONAL APORTADA NA PROPOSTA DE TRABALHOS COM PESQUISA
}

\author{
PROJECT METHODOLOGY: WAYS TO A SOCIAL AND \\ EDUCATIONAL TEACHING PRACTICE BASED ON THE BASIS \\ OF RESEARCH WORKS
}

\author{
Josimeri Grein ${ }^{1}$ \\ Maria de Fátima Quintal de Freitas ${ }^{2}$ \\ Lucymara Carpim $^{3}$
}

\begin{abstract}
RESUMO
Este artigo é o resultado de uma investigação realizada com oito professoras que atuam como multiplicadoras da metodologia de projetos em escolas estaduais e municipais do estado do Paraná, a partir da problemática: como elas percebem seu papel como agentes de transformação e de mudança junto aos participantes dos programas de formação continuada, considerando a metodologia de projetos? De abordagem qualitativa do tipo interpretativo, a pesquisa teve como objetivo verificar se a metodologia de projetos contribui para que ocorra o envolvimento dos alunos e demais agentes da escola e da comunidade e favorece a aprendizagem, beneficiando-os na resolução de problema sociais e educacionais. Para compor os resultados, optou-se pela análise de conteúdo, considerando a categorização das respostas obtidas, tendo como aporte epistemológico e conceitual os autores: Bardin (2010), Behrens (2005, 2006, 2014), Bender (2014), Freitas (2005), Hernandez (1998), Lane (1981, 1995), Torres $(2000,2014)$ e Veiga $(1996,1998,2009)$, que foram essenciais para dar suporte às investigações. As multiplicadoras investigadas apontaram a importância de seu papel como agentes de transformação da prática educativa dos professores participantes dos programas de formação continuada, considerando a metodologia de projetos possibilidade de uma aprendizagem significativa, que, por meio do envolvimento dos demais atores da escola e da comunidade, podem promover ações sociais e educacionais de maneira coletiva e colaborativa, que solucionem questões sociais e educacionais que afetam a realidade dos alunos e da sociedade.
\end{abstract}

Palavras-chave: Aprendizagem significativa. Metodologia de projetos. Trabalho colaborativo.

\section{ABSTRACT}

This article is the result of an investigation with eight teachers who act as multipliers of the project methodology in state and municipal schools in the

\footnotetext{
${ }^{1}$ Mestre em Educação (UFPR), Doutoranda no Programa de Pós-Graduação em Educação (PPGE) da Universidade Federal do Paraná (UFPR), Núcleo de Psicologia Comunitária, Educação e Saúde (NUPCES), josi.grein@ hotmail.com. http://lattes.cnpq.br/3824441220182627. https://orcid.org/0000-0002-3169-4012.

2 Doutora em Psicologia Social (PUC-SP), Pós-doutora Psicologia Comunitária (ISPA, Un. Porto, Portugal), Professora Titular do Programa de Pós-Graduação em Educação (PPGE) da Universidade Federal do Paraná (UFPR), Núcleo de Psicologia Comunitária, Educação e Saúde (NUPCES), $\quad$ fquintal@terra.com.br. $\quad \underline{\text { http://lattes.cnpq.br/4983108112468250 }}$ https://orcid.org/0000-0002-0414-199X.

3 Doutora e Mestre em Educação, Professora da UNICURITIBA, Graduada em Pedagogia e Letras, Especialista Em Didática do Ensino Superior, Gestão Educacional, Gerenciamento Ambiental na Indústria, Economia do Trabalho e Marketing Empresarial,

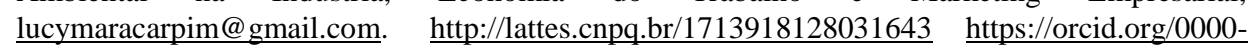
$\underline{0003-3549-979}$ 
state of Paraná, based on the research problem: how they see their role as agents of transformation and change with the participants in continuing education programs, considering the project methodology? With a qualitative approach of the interpretive type, the research aimed to verify whether the project methodology contributes to the involvement of students and other school and community agents and favors learning, benefiting them in solving social and educational problems. To compose the results, we opted for content analysis, considering the categorization of the responses obtained, having as epistemological and conceptual contribution the authors: Bardin (2010), Behrens (2005, 2006, 2014), Bender (2014), Freitas (2005), Hernandez (1998), Lane (1981, 1995), Torres $(2000,2014)$ and Veiga (1996, 1998, 2009), which were essential to support the investigations. The investigated multipliers pointed out the importance of their role as agents for transforming the educational practice of teachers participating in continuing education programs, considering the project methodology as the possibility of meaningful learning, which, through the involvement of the other actors of the school and the community, can promote social and educational actions in a collective and collaborative way, which solve social and educational issues that affect the reality of students and society.

Keywords: Collaborative work. Meaningful learning. Project methodology.

\section{INTRODUÇÃO}

As reflexões apontadas neste texto referem-se a uma investigação sobre a adoção da metodologia de projetos e como essa proposta de trabalho docente pode contribuir para que as ações educacionais e sociais sejam inovadoras e levem os professores a adotar a pesquisa como um caminho para que o ensino se concretize de maneira significativa, estimulando os alunos a "aprender a aprender", de maneira colaborativa e cooperativa.

A metodologia de projetos tem sido foco de muitas pesquisas quanto à sua adoção no ambiente escolar e social, pois se trata de uma proposta de ensino que objetiva envolver os estudantes em atividades dinâmicas, direcionadas a um trabalho que provoque investigações, argumentações, produções e criações a partir de problematizações surgidas ao longo das ações educativas, com reflexo no contexto social e comunitário.

A proposta do trabalho com projetos tem o propósito de fazer com que estudantes e professores repensem o papel da escola, do ensino e da aprendizagem, como um espaço de construção de saberes significativos e que possam ser aplicados na vida do aluno, tanto nos aspectos sociais e políticos quanto culturais e educacionais. O professor, ao propor projetos que estimulem as investigações individuais e coletivas, pode levar os discentes à construção de significados com relação aos temas estudados. Além disso, as oportunidades de acesso às informações por meio dos diversos canais de pesquisa disponíveis e a possibilidade que o aluno tem de contar com o apoio de diversos atores sociais trazem um novo olhar para o papel da escola e da educação, ao ressignificar e transpor ações conservadoras de ensino, com relação à produção do conhecimento e sua aplicabilidade na realidade educacional e social dos indivíduos.

Nas considerações de Lopes (2016, p. 22): 
a pedagogia de projetos visa a ressignificação do espaço escolar, transformando-o em um espaço vivo de interações, aberto ao real e às suas múltiplas dimensões, trazendo uma nova perspectiva para se entender o processo de ensino aprendizagem. Nesse processo, todo conhecimento é construído em estreita relação com os contextos em que são utilizados, sendo impossível separar os aspectos cognitivos, emocionais e sociais, pois a formação dos alunos não pode ser pensada apenas como uma atividade intelectual [...].

A partir dessa perspectiva, optou-se por uma investigação com oito professoras, multiplicadoras da metodologia de projetos, que atuam na formação continuada de docentes, em escolas particulares, municipais e estaduais do estado do Paraná e propõem um trabalho pedagógico que leve os educadores participantes dos programas de formação a compreender e adotar a pesquisa como possibilidade de integrar os saberes sistematizados, a partir do envolvimento dos discentes no processo educativo, de modo "empolgante e inovador, no qual os alunos selecionam muitos aspectos de sua tarefa e são motivados por problemas do mundo real que podem, e em muitos casos irão, contribuir com sua comunidade” (BENDER, 2014, p. $15)$.

As investigações realizadas para a composição deste artigo foram direcionadas pela seguinte problemática: como as multiplicadoras participantes percebem seu papel como agentes de transformação e de mudança, a partir da condução de sua ação docente junto aos professores que participam dos programas de formação continuada, considerando a metodologia de projetos? O percurso metodológico da pesquisa deu-se por meio de abordagem qualitativa de natureza interpretativa, considerando a análise de conteúdos como suporte para apresentação dos resultados obtidos, tendo como aporte investigativo autores como Bardin (2010), Behrens (2005, 2006, 2014), Bender (2014), Freitas (2005), Hernandez (1998), Lane (1981, 1995) e Torres (2000, 2014).

Entende-se que a metodologia de projetos visa a um trabalho pedagógico que leve os educadores a adotar a pesquisa como um caminho que permita aos alunos discutir e compreender os aspectos educacionais, sociais, culturais, políticos e econômicos, por meio de investigações para a resolução de problemas reais, considerando a possibilidade de participação dos diversos atores da escola, dos pais e da comunidade em que vivem.

A investigação foi estruturada em quatro seções: a primeira trata da metodologia de projetos e das ações docentes que envolvem alunos, professores e comunidade; a segunda apresenta o professor e seu papel como agente transformador social e educacional; a terceira apresenta os caminhos da pesquisa; e a quarta as considerações finais.

\section{METODOLOGIA DE PROJETOS: AÇÕES DOCENTES QUE ENVOLVEM ALUNOS, PROFESSORES E COMUNIDADE}


O processo educativo tem exigido dos docentes novos olhares para sua prática pedagógica, tendo em vista o perfil dos estudantes no atual cenário social e escolar, pois eles são mais conectados e informados e, muitas vezes, os temas trabalhados em sala de aula já foram objeto de investigação nas mídias e demais fontes de leitura, como jornais, revistas, livros e internet. Uma das temáticas apresentadas como possibilidade para que os discentes interajam com os saberes de maneira significativa e transponham os muros da escola é a metodologia de projetos, que, por meio da adoção de problematizações do entorno desses indivíduos, pode levá-los a refletir sobre sua realidade educacional e social, tendo a pesquisa como suporte educativo, além de favorecer e contribuir para que professores, alunos e comunidade apreendam de forma colaborativa.

Segundo aponta Veiga (2014, p. 336):

a docência é concretizada por meio da mediação de professores quando eles criam um ambiente de aprendizagem favorável, no qual os estudantes se sentem autônomos para expressar suas incertezas, questionar, argumentar, propor soluções sobre os problemas relacionados ao tema em estudo [...].

Muitas escolas já têm adotado a metodologia de projetos, por ela permitir trabalhar conteúdos e temas compostos pelas matrizes curriculares de forma mais dialógica e cooperativa, incentivando os estudantes a se comprometer e compreender situações de sua realidade de vida.

O grupo de professoras investigadas são multiplicadoras dessa proposta metodológica de ensino em um programa de formação continuada de nível estadual, cujo objetivo é orientar os docentes dessas instituições de ensino a envolver seus alunos em projetos de pesquisa, contribuindo para a adoção de práticas educativas inovadoras e interativas. A instituição replicadora dessa metodologia de ensino possui vários programas educativos que visam a contribuir com os professores da rede pública e particular de ensino para que adotem em sua ação docente a interdisciplinaridade e a transversalidade na construção de novos saberes educacionais e sociais pelos alunos, especialmente a partir do trabalho colaborativo, para o qual a metodologia de projetos direciona.

De acordo com Torres (2014, p. 20),

a proposta colaborativa faz que, ao desenvolverem atividades em equipe, a organização pessoal, o ritmo e a metodologia de trabalho, a noção de diferentes enfoques e indagações sobre o trabalho promova tanto o autoconhecimento quanto o conhecimento e desenvolvimento do aluno como membro de um grupo, ao mesmo tempo em que se tem o fortalecimento do grupo.

A metodologia de projetos é uma proposta educativa que objetiva, por meio de investigações individuais ou grupais, apontar problematizações e desafios, podendo (e 
devendo) os estudantes exprimir ideias e dúvidas, questionar os saberes já elaborados, construindo e reconstruindo significações individual e coletivamente, para que sejam aplicados em sua realidade pessoal, educacional e social. Trata-se de um trabalho interdisciplinar, sendo a interdisciplinaridade entendida, conforme Zabala (2002, p. 33), como

a interação de duas ou mais disciplinas. Essas interações podem implicar transferências de leis de uma disciplina a outra, originando, em alguns casos, um novo corpo disciplinar, como, por exemplo, a bioquímica ou a psicolinguística. Podemos encontrar essa concepção nas áreas de ciências sociais e experimentais no ensino médio e na área de conhecimento do meio do ensino fundamental.

A interdisciplinaridade permite transpor conteúdos de uma disciplina para outra, produzindo novas construções de saberes e análises críticas pelo aluno e, consequentemente, novas descobertas epistemológicas. Nesse contexto, o papel do professor é essencial, pois requer que também trabalhe coletivamente, compondo um núcleo de pesquisa e aprendizagem na escola, o que demanda planejar colaborativamente as ações, tanto pela equipe pedagógica quanto pelos estudantes, permitindo, dessa forma, reorganizar o trabalho educativo, quando docentes e discentes, em conjunto, buscam soluções possíveis para determinado problema.

Para Moraes (2008, p. 117),

[...] podemos dizer que a interdisciplinaridade é um princípio epistemológico que se modela mediante as atitudes dos sujeitos no ato de conhecer. Como princípio epistemológico é um instrumento para a criação, construção e compreensão do conhecimento. É, portanto, um dos caminhos do conhecimento.

Esse conhecimento pode ser percorrido por meio de ações que envolvam outros atores da escola e da sociedade, pois a aprendizagem se concretiza nos intercâmbios sociais e culturais que o aluno vive, quando diferentes conversações ocorrem. Além disso, os questionamentos e as incompreensões cotidianos podem ser vivenciados pelos estudantes, a partir do envolvimento coletivo nos projetos de pesquisa.

É importante observar que a pesquisa remete ao envolvimento com o processo formativo; nesse sentido, "acredita-se que a prática de formar pela pesquisa seja uma maneira de abordar e problematizar a visão do ser professor, de tornar os acadêmicos em formação, mais críticos e participativos [...]" (MAIA E FERNANDES, 2020, p. 76). Assim, a metodologia de projetos pode ser composta a partir de temas transversais, pois, conforme relatam Torres e Bochniak (2003, p. 3):

sabe-se que diversas são as experiências de colocação dos princípios da 'transversalidade' e da 'interdisciplinaridade' em prática, assim como se sabe, também, que a efetiva transposição ainda não foi concretizada, na maioria das escolas. Faz-se necessário, concretizar a implementação desse eixo epistemológico, buscando uma proposta metodológica coerente com os princípios teóricos estabelecidos, pois, percebe-se, de fato, que especialmente em relação às questões da 
'interdisciplinaridade' e da 'transversalidade' a escola ainda se encontra diante de um enorme descompasso entre teoria e prática.

Os aspectos transversais e interdisciplinares são pouco explorados nos ambientes educativos, o que demanda ações educativas que provoquem os estudantes a participar ativamente de ações educativas que promovam transformações educacionais e sociais, de maneira crítica e responsável. Sobre os temas transversais, Menezes e Santos (2001, p. 3) afirmam que:

são temas que estão voltados para a compreensão e a para a construção da realidade social e dos direitos e responsabilidades relacionados com a vida pessoal e coletiva e com a afirmação do princípio da participação política. Isso significa que devem ser trabalhados, de forma transversal, nas áreas e/ou disciplinas já existentes.

Portanto, os temas transversais referem-se às questões presentes em vários aspectos da vida cotidiana social e educacional dos indivíduos. Nessa perspectiva, explorá-los na metodologia de projetos permite, de acordo com Hernandez (1998, p. 61):

\begin{abstract}
aproximar-se da identidade dos alunos e favorecer a construção da subjetividade, longe de um prisma paternalista, gerencial ou psicologista, o que implica considerar que a função da escola não é apenas ensinar conteúdos, nem vincular a instrução de situá-lo no tempo e nos espaços escolares. O que torna necessária a proposta de um currículo que não seja uma representação do conhecimento fragmentada, distanciada dos problemas que os alunos vivem e necessitam responder em suas vidas, mas, sim, solução de continuidade. Levar em conta o que acontece fora da escola. Nas transformações sociais e nos saberes, a enorme produção de informação que caracteriza a sociedade atual, e aprender a dialogar de uma maneira crítica com todos esses fenômenos.
\end{abstract}

Para tanto, a postura docente necessita oportunizar que os estudantes interajam com outros agentes mediante projetos escolares que envolvam significações sociais e culturais, especialmente fora do espaço da sala de aula. A proposta é que as experiências educativas se conectem com a construção de saberes, a partir de práticas vividas individual e coletivamente, com respeito à realidade educacional e social. Com base nas situações propostas nos projetos a partir de problemas existentes na realidade do aluno, a construção e a resolução dos problemas devem ser desenvolvidas de maneira coletiva e colaborativa, processo em que os professores são os orientadores e mediadores dos saberes, permitindo que o espaço escolar se torne espaço vivo, contribuindo para que mudanças significativas ocorram, transformando os alunos em seres críticos, reflexivos e conscientes de que podem mudar sua realidade educacional e social. Já o aluno, na metodologia de projetos, tem um papel a ser cumprido, assumindo responsabilidades, como coparticipante das ações de investigação, por meio de um envolvimento concreto nas pesquisas, na troca de informações com seus pares, nos estudos e no compartilhamento de suas dúvidas e descobertas, de maneira dialógica.

Nas considerações de Silva e Tavares (2010, p. 240): 
o método por projetos propõe que os saberes estejam integrados com os saberes sociais, pois ao estudar o aluno sentirá que está aprendendo algo que já faz sentido e tem significado em sua vida, assim compreende o seu valor e desenvolve uma postura indispensável para a resolução de problemas sociais atuando como sujeito cultural e educacional.

Nessa maneira de conduzir a prática docente, o educador deve estimular o aluno a compreender sua realidade social, que pode ser explorada, compondo um caminho em que temas transversais são considerados, a fim de promover o despertar criativo, levando o estudante a acessar sua história cultural e social e os desafios que nela existem para compreender como suas capacidades cognitivas e socioemocionais podem auxiliar para construir uma sociedade mais justa e inclusiva.

A compreensão do ser cidadão e de participar social e politicamente da sociedade, exercendo direitos e deveres civis, políticos e sociais no dia a dia, pode ser orientada no ambiente educativo, a partir do saber sistematizado. Igualmente, olhares para o respeito, a solidariedade e a cooperação com o outro, nas diferentes situações de vida do estudante, podem ser explorados nas atividades. Nesse contexto, o posicionamento do aluno deve envolver a criticidade, a reflexão e o compromisso responsável e construtivo, considerando as diferentes situações surgidas durante as investigações, envolvendo-se no projeto de maneira dialógica e entendendo que exige a tomada de decisões a partir de um posicionamento frente aos desafios e descobertas surgidos no caminhar da sua participação no projeto. Nas palavras de Behrens (2006, p. 38):

a metodologia de projetos pode incentivar a habilidade de escolher, de valorizar a si mesmo e ao grupo, de conviver em situações de consenso, de aceitar e analisar com respeito os posicionamentos de outras pessoas, de construir processos de autoconfiança que permitam atuar com competência e independência.

É na instituição escola que o saber sistematizado é explorado. Dessa forma, ao desenvolver projetos em que a pesquisa é o direcionamento para uma aprendizagem significativa, o professor pode propor, na sua ação docente, a socialização das descobertas e dúvidas, assim como sua aplicabilidade imediata pelos estudantes em sua realidade de vida. Por meio da aplicação dos resultados obtidos nas pesquisas, é possível, conforme Silva e Tavares (2010, p 237), “[...] desenvolver conceitos, atitudes, valores éticos, liderança, sociabilidade e capacidade de resolução de problemas contribuindo de maneira consciente com a sociedade". A ideia é transpor as limitações de um cotidiano centrado apenas no ambiente educativo e envolver os atores da comunidade em que os alunos vivem. Assim, o estudante assume um papel ativo, participativo, não seguindo livros didáticos com temas 
preestabelecidos, mas, sim, atividades que possam ser compartilhadas e aplicadas como princípio de igualdade de oportunidades.

O principal agente de mudança para que a proposta da pesquisa seja ancorada no ambiente educativo é o professor, que passa a ter o papel de mediador, tornando-se, com seus discentes, também um pesquisador crítico, articulando os saberes de maneira reflexiva e interativa. Além disso, nas orientações de Veiga (2009, p. 58), “ensinar a pesquisa significa estimular a criatividade, o espírito investigativo, a curiosidade. A pesquisa é uma atividade inerente ao ser humano, um modo de aprender o mundo. Ensinar a pesquisa é tomar a pesquisa como instrumento de ensino, de aprendizagem e avaliação [...]". Os projetos permitem ao aluno aprender fazendo, reconhecendo sua caminhada de aprendizagem, pois, a partir das investigações com vistas à resolução de problemas reais existentes, ele se envolve com seus colegas na contextualização das temáticas investigadas, possibilitando descobrir outros caminhos, compreender que dúvidas são essenciais para a concretização da aprendizagem.

Para Silva e Tavares (2010, p. 240):

\begin{abstract}
a pedagogia de projetos propõe então mudanças na postura pedagógica, além de oportunizar ao aluno um jeito novo de aprender, direcionando $o$ ensino/aprendizagem na interação e no envolvimento dos alunos com as expectativas educativas que se integram na construção do conhecimento com as práticas vividas, no momento da construção e resolução de uma determinada situação/problema, o que possibilita transformar o espaço escolar em espaço vivo, colaborando para mudanças significativas no ensino e para a formação dos alunos como seres autônomos, conscientes, reflexivos, participativos [...].
\end{abstract}

A possibilidade de interação entre alunos e professores no contexto educativo é maior, pois, a partir da busca pela resolução de problemas, ocorre o envolvimento de todos no processo de ensino e na coautoria da aprendizagem. O professor, nesse contexto, necessita repensar a sua prática pedagógica, articulando descobertas e contribuindo para a transposição dos novos saberes para a realidade social dos alunos, envolvendo seus familiares, amigos e demais sujeitos da comunidade, a fim de transformar a sala de aula em um espaço de ressignificações de saberes.

Segundo Behrens (2014, p. 95):

a nova realidade da sociedade do conhecimento tem desafiado o professor a repensar a prática pedagógica e se tornar um investigador, articulador, mediador e pesquisador crítico e reflexivo. Nesse contexto, além de um profissional competente, precisar tornar-se um cidadão autônomo e criativo que saiba solucionar problemas e manter constante iniciativa para questionar a transformar a sociedade.

O papel do docente, na metodologia de projetos, é desafiador, porém os caminhos possíveis para adoção de atividades que envolvam alunos e a sociedade a que pertencem em 
ações educativas inclusivas existem e podem ser implantados e implementados na busca de soluções sociais e culturais, desde que haja comprometimento e envolvimento de todos, especialmente dos docentes, como agentes de mudança do processo educacional.

\title{
O PROFESSOR: SEU PAPEL COMO AGENTE TRANSFORMADOR SOCIAL E EDUCACIONAL
}

Para que a metodologia de projetos se consolide em sala de aula e transponha os muros da escola, o papel do professor é essencial como agente mediador dos projetos e das pesquisas, pois sua ação pedagógica inovadora junto aos alunos, demais profissionais da escola, pais e comunidade é fundamental no processo educativo. Segundo Behrens (2014, p. 105), na pedagogia de projetos, “[...] tanto os alunos como os professores pensam, leem, questionam suas próprias ideias e interagem com seus colegas, compartilham suas inseguranças, tornando esta interação enriquecida mutuamente".

A pesquisa necessita ser conduzida pela escola como um processo vivo e dinâmico, com atividades que envolvam os estudantes em situações que possam ser pensadas e repensadas à luz de questões reais, focando o trabalho coletivo dos alunos na atuação para um bem maior, educacional, cultural e social. O professor é agente essencial nesse contexto; conforme considerações de Behrens (2005, p. 82):

\begin{abstract}
o professor, na metodologia de ensino com pesquisa, torna-se figura significativa no processo como orquestrador da construção do conhecimento. Tem a função de ser mediador, articulador crítico e criativo do processo pedagógico. Como produtor de seu próprio conhecimento, instiga o aluno a 'aprender a aprender', centrando sua competência estimuladora no ensino com pesquisa. Orienta os alunos para se expressarem de maneira fundamentada, exercitando o questionamento e a formulação própria.
\end{abstract}

Trata-se de um papel de articulação da construção histórica de saberes do aluno como indivíduo de uma sociedade que se forma e se transforma continuamente, pois o grupo de estudantes, ao interagir e buscar possíveis soluções para determinado problema de uma comunidade em especial ou de várias, estabelece vínculos, a fim de tratar de necessidades comuns existentes na realidade educacional e social.

A criação de grupos no ambiente educativo proporciona uma conexão mais concreta com a formação e estruturação de uma consciência mais comprometida com os desafios educacionais e sociais, o que vem ao encontro do que destaca Freitas (2005, p. 50):

[...] deparamo-nos com o desenvolvimento de programas de ação coletiva e grupal, com reuniões e grupos orgânicos, e a implementação de grupos-atividades a partir dos recursos existentes (materiais e humanos) e das necessidades vividas pelas pessoas diante de problemas de natureza estrutural, objetivando a formação de 
consciência, o fortalecimento dos processos de subjetivação e a construção de relações mais cooperativas.

Compor grupos para atuar de maneira coletiva e cooperativa requer um docente que oriente alunos e demais participantes dos projetos na caminhada para obter resultados que tragam benefícios para a comunidade, como também aprendizagem significativa para alunos e demais envolvidos. O professor tem o papel de articular os saberes construídos e as possibilidades de aplicação destes na ação comunitária, considerando que o ambiente educativo tem o propósito de construir conhecimentos a partir da interação com os outros saberes. Seu papel, portanto, é contribuir na construção e reconstrução de saberes.

Ao propor o trabalho com projetos, o docente deve compreender que o envolvimento coletivo e colaborativo se refere também ao corpo docente da escola, que, em conjunto, pode promover um trabalho interdisciplinar, transversal e inovador na condução das pesquisas, conforme destaca Ventura (2002, p. 5):

Em primeiro lugar consideramos que os projetos devem ter uma dimensão interdisciplinar: um professor não precisaria reunir todas as competências necessárias para a realização dos projetos, mas competência para uma boa orientação. E quanto mais professores em condição de orientação, mais facilitados seriam os trabalhos e melhores os resultados.

Esse cenário requer uma escola e professores comprometidos e trabalhando de maneira conjunta, para facilitar uma aprendizagem que leve o aluno a participar das atividades, considerando a construção e reconstrução de saberes, de maneira crítica, reflexiva, autônoma e interativa. O sucesso do projeto está na responsabilidade do aluno frente aos desafios que surgem durante as investigações, na elaboração de propostas solucionadoras, assim como no professor ao conduzir a ação educativa, fortalecendo os laços de cooperação.

As relações consolidadas entre os grupos de estudantes investigadores podem levá-los à compreensão de que é na interação entre os diversos saberes compostos pelo grupo, integrados por meio das relações sociais e culturais, que se solidificam as resoluções dos questionamentos que emergem durante as pesquisas. Consoante Lane (1981, p. 68):

desenvolver relações sociais que se efetivem através da comunicação e cooperação entre pessoas, relações em que não haja dominação de uns sobre outros [...] desde que estes se identifiquem por necessidades comuns a serem satisfeitas, através de atividades planejadas em conjunto e que impliquem ações de vários indivíduos [...].

É necessariamente por meio do trabalho colaborativo e cooperativo que os pares se conectam para resolver situações que individualmente seriam impossíveis. Nessa dinâmica, o docente necessita apresentar aos estudantes caminhos que os levem a se unir em suas comunidades, tendo como embasamento o ambiente educacional, apresentando proposta de 
trabalhos coletivos, em que os esforços dos grupos permitam a aprendizagem educacional e social. Para Martins (2007, p. 79):

isoladamente, a pessoa identifica o seu problema como exclusivo, como necessidade individual. No entanto, ao se reunirem, os indivíduos percebem que os problemas, muitas vezes semelhantes, são decorrentes das próprias condições sociais de vida e que a organização coletiva, diferente da ação individual isolada, pode propiciar a resolução de problemas ou a satisfação de necessidades comuns.

Por conta disso, destaca-se a importância do trabalho com projetos nas escolas, pois eles permitem que o envolvimento colaborativo desperte os estudantes para juntos, construir novos cenários educacionais e sociais. Para orientá-los, os docentes precisam assumir que mudanças na sua prática educacional são essenciais para que o saber compartilhado se concretize. Como disserta Behrens (2006, p. 45-46), os projetos levam os alunos a outras dimensões na construção dos saberes, pois:

a necessidade de oferecer uma aprendizagem que leve à autonomia pessoal, ao espírito crítico-reflexivo, à formação de valores éticos e solidários, pressupõe processo que propicie envolvimento e responsabilidade no sentido de buscar atitudes baseadas na democracia e na participação. A metodologia de projetos representa uma perspectiva pedagógica relevante, pois trabalhar a partir de problemas representa possibilitar novas atividades e novas maneiras de acessar o conhecimento e de aprender.

Os projetos oportunizam aos alunos se envolver em sua própria aprendizagem, cabendo ao docente mediar esse processo, por meio da adoção de prática de ensino inovadora, na qual estudantes, comunidade e escola caminhem na busca de saberes significativos e aplicáveis à realidade social, educacional e cultural dos discentes e das comunidades a que pertencem.

Portanto, o educador precisa desenvolver um olhar que transponha práticas conservadoras de ensino e adotar metodologia que permita a concretização da aprendizagem por meio de pesquisas que envolvam os alunos no processo de aprender a aprender, tanto em sala de aula quanto em outros cenários, favorecendo sua autonomia com relação à própria construção de conhecimentos significativos.

\section{CAMINHOS DA PESQUISA}

A investigação contemplou uma pesquisa de abordagem qualitativa de natureza interpretativa com oito professoras que atuam como multiplicadoras da metodologia de projetos, a partir da seguinte questão orientadora: como elas percebem seu papel como 
agentes de transformação e de mudança junto aos participantes dos programas de formação continuada, considerando a metodologia de projetos?

Elaborou-se um questionário semiestruturado, o qual foi aplicado às multiplicadoras, que responderam a três questionamentos: (i) como percebem seu papel como agentes de mudança com relação à aplicabilidade da metodologia de projetos; (ii) se acreditam que a metodologia de projetos contribui para que os professores envolvam alunos, demais atores da escola, pais e comunidade nas ações educacionais e sociais; (iii) se a metodologia de projetos pode favorecer a aprendizagem, beneficiando alunos e comunidade na resolução de problemas sociais e educacionais.

$\mathrm{Na}$ proposta da pesquisa qualitativa, que busca significados a partir do universo de possíveis relações entre os processos e os fenômenos, considerando o caráter científico da investigação, é interessante o que observa Flick (2009, p. 9):

A pesquisa qualitativa parte da ideia de que os métodos e a teoria devem ser adequados àquilo que se estuda. Se os métodos existentes não se ajustam a uma determinada questão ou a um campo concreto, eles serão adaptados ou novos métodos e novas abordagens serão desenvolvidos.

Portanto, a qualidade da investigação está nos argumentos utilizados pelos autores para defender uma ideia, no caso, a metodologia de projetos.

Quanto à natureza da pesquisa, optou-se pelo tipo interpretativo, que leva à interpretação das respostas dos participantes, contemplando também suas entrelinhas. Assim, foi realizada mediante análise das ideias expostas, reflexões e considerações apontadas pelas multiplicadoras, participantes da investigação. Nas considerações de Severino (2007, p. 59), na análise interpretativa,

[...] busca-se uma compreensão interpretativa do pensamento exposto e explicitamse os pressupostos que o texto implica. Tais pressupostos são ideias nem sempre claramente expressas no texto, são princípios que justificam, muitas vezes, a posição assumida pelo autor, tornando-a mais coerente dentro de uma estrutura rigorosa.

Dessa forma, a análise interpretativa apresenta concepções que se caracterizam por ações e comportamentos observáveis tanto no aspecto social quanto individual, estabelecendo conexões entre a psicologia social e a sociologia (LANE, 1995). Por conta disso, as colocações postas pelas professoras investigadas refletem um conjunto de ideias, num processo ativo de envolvimento com a prática docente, a partir da multiplicação da metodologia de projetos. 
As respostas foram categorizadas a partir das expressões e reflexões mais relevantes que emergiram delas, classificando-se, com isso, elementos constitutivos da pesquisa, conforme destaca Bardin (2010, p. 145):

A categorização é uma operação de classificação de elementos constitutivos de um conjunto por diferenciação, e seguidamente, por reagrupamento segundo gênero (analogia), com os critérios previamente definidos. As categorias são rubricadas em classes, as quais reúnem um grupo de elementos (unidades de registro, no caso da análise de conteúdo) sob um título genérico, agrupamento esse efetuado em razão das características comuns destes elementos.

A partir da categorização das respostas obtidas, foi efetuada a análise de conteúdo, que permitiu verificar a presença de determinadas características, levando à melhor compreensão da construção de significado que os atores sociais e educacionais exteriorizaram nas suas respostas. Frisa-se que sua escolha como metodologia para apresentação dos resultados deveu-se às respostas obtidas nas três perguntas propostas. Nesse cenário, a análise de conteúdo permitiu discorrer sobre as concepções que as professoras apresentaram em relação à sua realidade como multiplicadoras da metodologia de projetos e as interpretações e reflexões que fazem sobre seu papel educativo.

\section{CATEGORIZAÇÃO E REFLEXÕES APONTADAS PELAS PROFESSORAS INVESTIGADAS}

As respostas obtidas permitiram considerar posicionamentos bem definidos quanto ao papel das professoras multiplicadoras da metodologia de projetos, iniciando pela sua percepção no tocante ao seu papel como agentes de mudança com relação à aplicabilidade da metodologia de projetos. Ao analisar as respostas, consideraram-se relevantes dois pontos, os quais foram categorizados: trabalho colaborativo e despertar a compreensão do senso crítico e reflexivo dos professores. A esse respeito, as participantes relataram:

P1: Meu papel principal é o de orientar os professores de como a metodologia de projetos permite um trabalho colaborativo, envolvendo os alunos e professores em atividades que transponham os muros da escola, e que a sociedade possa contribuir com desafios e problemas reais que envolvem todos da comunidade e da escola.

P2: Refletir junto com os professores sobre a mudança de perfil dos alunos, requerendo também mudanças na postura docente e na prática pedagógica. Uma ação educativa que envolva a pesquisa como instrumento de investigação individual e colaborativa.

P3: Meu papel é incentivar os professores a adotar a metodologia de projetos, para envolver alunos e comunidade em um trabalho colaborativo e cooperativo, permitindo nesse sentido a construção de olhares críticos e reflexivos sobre os problemas reais pelos quais alunos, professores, pais e comunidade enfrentam. 
P7: Mostrar que os professores e alunos são fazedores da própria história e que a ação conjunta e colaborativa transforma o processo de ensino e aprendizagem e a visão de mundo e de sociedade.

Essas colocações apresentam a aprendizagem colaborativa como necessária na metodologia de projetos, pois a socialização do conhecimento e o trabalho conjunto contribuem para uma dinâmica educacional e social, tornando o estudante um agente de mudança da sua realidade.

Para Torres e Irala (2014, p. 65):

em uma visão mais ampla do que significa aprender colaborativamente, pode-se dizer que, de maneira geral, espera-se que ocorra a aprendizagem como efeito colateral de uma interação entre pares que trabalham em sistema de interdependência na resolução de problemas ou na realização de uma tarefa proposta pelo professor $[\ldots]$.

Compreende-se que a colaboração estimula e permite a troca de saberes, dúvidas e ideias, favorecendo um trabalho significativo e que pode ser aplicado na prática de vida dos indivíduos.

Sobre o papel de despertar a compreensão do senso crítico e reflexivo dos professores, as docentes indicaram:

P4: Os professores no contexto da metodologia de projetos necessitam despertar nos alunos envolvidos nas atividades um olhar crítico sobre sua própria aprendizagem, compreendendo que esta deve contribuir para a sistematização do conhecimento a partir da reflexão do aprender a aprender. Colocar em prática os saberes construídos.

P6: A pesquisa enquanto caminhos de descobertas e dúvidas conduz a reflexão do porquê estudar um determinado tema e de como este reflete a realidade dos alunos nos aspectos sociais, culturais, educacionais e políticos. A proposta da pedagogia da pesquisa é de permitir que os estudantes discutam e reelaborem suas estruturas cognitivas e atuem coletivamente na resolução de problemas que podem existir na vida dos alunos.

P8: Pesquisar é dar sentido ao que está aprendendo. Aprender com consciência de que o que se está aprendendo tem sentido e que este se faz a partir do ato de reflexão. Despertar o senso crítico social e cultural a partir da prática do que se está aprendendo. Contextualizar a teoria com a prática. Estudantes como sujeitos ativos. O homem se percebe como agente social e o conhecimento contribui para a interpretação da sua própria realidade.

Por essas considerações, percebe-se a coerência necessária entre a teoria e a prática educativa, com finalidade não apenas de transmissão de conteúdos prontos, mas, a partir de 
um ambiente educativo que atue como ponte entre informações, conhecimentos e concepções sociais, levar os estudantes à compreensão significativa do conhecimento. Consoante Veiga (1996, p. 160),

o ensino é uma atividade profissional complexa que exige preparo, compromisso e responsabilidade do educador para instrumentalizar política e tecnicamente, o aluno, ajudando-o a constituir-se como sujeito social. Ensinar para a compreensão significa a existência de uma estreita relação entre professor e aluno.

A relação indicada por Veiga (1996) propõe a superação do ensino visto apenas como instrumento para a transmissão dos conhecimentos, na direção de uma organização do trabalho docente em que o indivíduo seja visto como pensador ativo, consolidando-se, entre as interações sociais dos grupos criados no ambiente educativo, a visão de pertença de outros indivíduos socialmente comprometidos com a comunidade, na construção política e social na sua realidade de vida.

Os projetos desenvolvidos pelas escolas necessitam contemplar a convivência dos estudantes nas comunidades, os quais devem atuar como atores sociais e educacionais, dentro das realidades vividas, com as redes de convivência se fortalecendo e se consolidando por meio de ações que considerem o compromisso político, social e educacional. Assim, uma vez que as práticas social e educacional estão imbricadas, a metodologia de projetos é um caminho que pode consolidar essa união, considerando projetos significativos e bem direcionados.

Na segunda questão, voltada a identificar se as multiplicadoras acreditam que a metodologia de projetos contribui para que os professores envolvam os alunos, demais atores da escola, pais e comunidade nas ações educativas e sociais, foram categorizadas as considerações: professores e alunos pesquisadores envolvidos na prática educacional e social; e projetos que permitem a construção e reconstrução de saberes de maneira coletiva, obtendo como referencial que professores e alunos devem buscar soluções sociais e educacionais de maneira coletiva, com as ações acontecendo dentro e fora dos muros da escola.

Seguem algumas considerações das professoras:

P1: A pesquisa em sala de aula necessita transpor o espaço educacional, para isso os projetos devem ser escolhidos pelos alunos em consonância com os professores $e$ que abordem temas que sejam relevantes tanto para a aprendizagem como para a prática social e educacional dos estudantes e demais atores envolvidos nos projetos. Nesse sentido, envolver pais, colegas e comunidade é essencial para assim tratar a pesquisa com foco em resolução de problemas e na aprendizagem do saber sistematizado.

P5: Por meio dos projetos de pesquisa envolver pais, professores e demais profissionais da escola e a sociedade é fundamental para que aprendizado tenha significado de maneira interdisciplinar e possa ser aplicado na realidade do aluno, 
valorizando seus saberes prévios e o que já entendem de sua realidade. Discentes $e$ docentes trabalhando para a ressignificação do saber a partir de um trabalho colaborativo. Transpor os muros da escola e envolver a comunidade é o grande desafio da metodologia de projetos.

P7: A metodologia de projetos estimula a construção do conhecimento em consonância com os desafios educacionais e das comunidades nas quais os alunos estão inseridos, identificar os sabres já apropriados, explorá-los, tendo em vista que o saber é construído pelos alunos considerando a resolução de situações de problemas reais vividos por eles em comunidade. É um trabalho interdisciplinar $e$ colaborativo.

P8: A metodologia de projetos permite que os objetos e investigação sejam direcionados para a resolução de problemas, envolvendo pais, alunos, professores $e$ outros envolvidos.

Pelas colocações apresentadas, as professoras investigadas mostram que a metodologia de projetos permite o envolvimento de pais, alunos, professores e comunidade, com vistas a possibilitar a construção de saberes educacionais e sociais significativos, como também desenvolver olhares de investigação que instiguem o envolvimento de outros atores sociais nas atividades e descobertas. Em consonância, Behrens (2014, p.100) afirma que

a metodologia de projetos pode auxiliar na ampliação da visão inter e transdisciplinar, pois representa um processo metodológico de aprendizagem que envolve níveis de integração, interconexão, inter-relacionamento de informações, agregação de informações, conteúdos, conhecimentos e saberes na busca de uma abordagem mais complexa.

Na proposta do trabalho com pesquisas, a primeira ação a ser tomada é a definição de uma situação problematizadora, valorizando os saberes prévios dos estudantes e envolvendoos nessa escolha, para que sejam participantes ativos e sintam-se responsáveis pelos caminhos que serão tomados, sempre com foco na aprendizagem significativa, para que esta seja aplicada em realidades sociais e educacionais, o que vem ao encontro do que declara Veiga (2014, p. 336): “É possível compreender que a docência problematizadora lança mão de conhecimentos prévios e já elaborados para pensar, raciocinar sobre eles e, a partir deles, formular soluções para os problemas de estudo [...]".

As professoras investigadas demonstram essa preocupação em identificar os saberes já construídos e, a partir deles, aprofundar as investigações, a fim de envolver todos na pesquisa, provocando os discentes a desenvolver um olhar crítico sobre sua própria aprendizagem. Isso exige um professor que pense e repense que, ao promover sua ação educativa, precisa mostrar aos estudantes que "o conhecimento é construído e transformado coletivamente" (VEIGA, 1998, p. 20).

Com relação ao último questionamento, que buscou verificar se a metodologia de projetos pode favorecer a aprendizagem, beneficiando alunos e comunidade na resolução de 
problemas sociais e educacionais, destacou-se a categorização: relação significativa de aprendizagem, presente nas seguintes respostas:

\begin{abstract}
P3: Os problemas levantados em sala de aula, a partir de situações reais vividas pelos alunos em sociedade, transformado em projetos com o envolvimento de alunos, professores, pais e comunidade levam a outras relações de significações. Os envolvidos em solucionar uma situação problema, as investigações, a prática da ação docente voltada para a aprendizagem significativa, consolida uma ação educacional e social que seja relevante para todos.
\end{abstract}

P5: Pais e alunos mais participativos no contexto escolar, o saber sistematizado transposto para uma prática real, pois nem sempre o professor consegue ensinar tudo para os alunos, quando a prática pedagógica envolve outros profissionais contribui para que o aluno e os pais percebem sua realidade de vida de maneira significativa com o processo de aprendizagem, e que esta faz parte de um contexto que pode ser compartilhado. A metodologia de projetos possibilita outras formas de aprender, não apenas no cenário de transmissão mais de participação.

P6: Os benefícios estão presentes na superação do ato de aprender para o fazer. $O$ conhecimento torna-se palpável, significativo, pois sua aplicabilidade traz resultados que favorecem pessoas. Ocorre uma relação significativa entre o que se está aprendendo e como isso pode ser aplicado na vida. A intensão é aproximar a realidade de vida do aluno com os conteúdos trabalhados na escola. Benefício para todos.

As significações das professoras são claras quanto aos benefícios possíveis na adoção pelo professor de práticas educacionais que considerem a metodologia de projetos. As concepções didáticas e pedagógicas, assim como os valores éticos e culturais, devem ser caracterizadas durante a ação docente para que venham a atender aos aspectos sociais e educacionais. Assim, durante o desenvolvimento dos projetos, os estudantes podem ser envolvidos nas atividades e atuar como participantes ativos na construção da própria aprendizagem. Nesse cenário, o papel do professor muda, não sendo o agente central do processo de ensino, mas, sim, um mediador da aprendizagem.

O fundamental na metodologia de projetos é o envolvimento de vários indivíduos, pois o conhecimento não fica estagnado, mas cria vida, torna-se dinâmico na sua concepção e construção. Nas palavras de Prado (2009, p. 4),

na pedagogia de projetos, o aluno aprende no processo de produzir, levantar dúvidas, pesquisar e criar relações que incentivam novas buscas, descobertas, compreensões e reconstruções de conhecimento. Portanto, o papel do professor deixa de ser aquele que ensina por meio da transmissão de informações - que tem como centro do processo a atuação do professor - para criar situações de aprendizagem cujo foco inicia sobre as relações que se estabelecem nesse processo, cabendo ao professor realizar as mediações necessárias para que o aluno possa encontrar sentido naquilo que está aprendendo a partir das relações criadas nessas situações.

Portanto, a prática docente, ao adotar a metodologia de projetos, requer um trabalho mais elaborado e coordenado, considerando a diversidade de alunos envolvidos, as questões 
sociais postas diariamente por eles e o envolvimento de outros agentes escolares e sociais. $\mathrm{O}$ estabelecimento de relações pessoais e coletivas por meio dos projetos permite que as conexões sociais e a coautoria dos vários protagonistas, tanto educacionais quanto demais atores da sociedade, se consolidem. Como afirma Veiga (1996, p. 159), “a visão do conhecimento está vinculada às visões de homem e de mundo que o aluno vai adquirir durante seu processo de escolarização [...]”, momento em que, na proposta do desenvolvimento de projetos, “[...] o aluno presta atenção, observa, faz anotações e exercícios, discute em grupo, estuda, exemplifica, generaliza, faz síntese integradora, expõe com as próprias palavras, toma consciência das dificuldades, usa materiais diversos, avalia, etc.” (VEIGA, 1996, p. 160).

Diante do exposto, se percebe a importância da adoção da metodologia de projetos no ambiente educacional e fora dele. Entretanto, são necessárias outras investigações, especialmente com relação à aplicabilidade dessa metodologia na prática. Como ponto inicial, é fundamental preparar os docentes para entender a proposta de adoção dessa metodologia e os caminhos possíveis com essa prática.

\section{CONSIDERAÇÕES FINAIS}

Pelas respostas obtidas na investigação, pode-se considerar que, ao orientar as escolas quanto à metodologia de projetos, as professoras pesquisadas percebem as possibilidades favoráveis de envolver professores, alunos e comunidades nos projetos escolares, por meio de problematizações comuns na sociedade em que os alunos convivem, entendendo que é possível a construção de saberes significativos e aplicáveis à realidade social e cultural dos envolvidos.

As participantes foram claras ao apontar a metodologia de projetos como um caminho essencial para envolver os pais e as comunidades em ações que reflitam a composição de saberes que levem os estudantes a desenvolver um olhar crítico para sua própria realidade de vida, a partir da compreensão de que ele pode mudá-la, considerando os aspectos educacionais, sociais e políticos ferramentas para tal. Ainda, os projetos podem consolidar a sistematização dos saberes na proposição de aprender a aprender, como também levar os estudantes a refletir sobre a construção do senso crítico social e cultural, percebendo-se como indivíduos da sociedade e, como tal, agindo em prol de mudanças e transformações de sua realidade. As respostas apontam que alunos envolvidos na resolução de problemas reais sociais e culturais dão um novo sentido àquilo que aprendem na escola, compreendendo que os conhecimentos podem ser aplicados respeitando a diversidade e que sua história de vida lhe dá subsídios para a resolução de problemas reais. 
Frisa-se, por fim, que os apontamentos aqui trazidos não se esgotam nesta investigação, pois muito ainda é necessário pesquisar para compreender com maior propriedade os benefícios educacionais e sociais, a importância da prática da metodologia de projetos nas escolas e sua aplicabilidade na realidade social e cultural a partir do envolvimento dos atores escolares e da comunidade.

\section{REFERÊNCIAS}

BARDIN, Laurence. Análise de conteúdo. Lisboa: Portugal, Edições 70, 2010.

BEHRENS, Marilda Aparecida. Metodologia de projetos: aprender e ensinar para a produção do conhecimento numa visão complexa. In: Complexidade: redes e conexões na produção do conhecimento. Coleção Agrinho, Curitiba: SENAR, 2014.

BEHRENS, Marilda Aparecida. O paradigma emergente e a prática pedagógica. Petrópolis: RJ, Vozes, 2005.

BEHRENS, Marilda Aparecida. Paradigma da complexidade: metodologia de projetos, contratos didáticos e portfólios. Petrópolis: RJ, Vozes, 2006.

BENDER, William N. Aprendizagem baseada em projetos: educação diferenciadas para o século XXI. Porto Alegre: Penso, 2014.

FLICK, Uwe. Desenho da pesquisa qualitativa. Porto Alegre: Artmed, 2009.

FREITAS, Maria de Fátima Quintal de. Coerências entre práticas psicossociais em comunidade e projetos de transformação social: aproximações entre as Psicologias Sociais da Libertação e Comunitária. PSICO, PUC-RS, v. 36, n. 1, jan/abr. 2005.p.47-54, Disponível em: http://revistaseletronicas.pucrs.br/ojs/index.php/revistapsico/article/view/1374/1074, acesso em 12 de maio de 2016.

HERNANDEZ, Fernando. Transgressão e mudança na educação: projetos de trabalho. Porto Alegre: ArtMed, 1998.

LANE, Sílvia Tatiana Maurer. O que é psicologia social. Vol. 39. Primeiros Passos, São Paulo: Brasiliense, 1981.

LANE, Silvia Tatiana Maurer. Usos e abusos do conceito de representações sociais. In: SPINK, M.T. (Org.). O conhecimento no cotidiano: as representações sociais na perspectiva da psicologia social. São Paulo: Brasiliense, 1995. P. 47-57.

LOPES, Rovena Monteiro. A pedagogia de projetos. Disponível em: $\mathrm{http} / /$ pedagogiaaopedaletra.com/resumo-a-pedagogia-de-projetos. Acesso em 12 de fevereiro de 2017.

MAIA, Mânia Maristane Nebes Silveira; FERNANDES, Luzia Leidjane Mendonça. Formação de professores: desafios e possibilidades sobre os sabres teóricos e práticos no processo formativo do acadêmico de pedagogia. Revista Ciranda, Montes Claros, v. 4. N. 2, 2020, p. 70-86. Disponível em: https:www.peridodicos.unimontes.br/index.php/ciranda/index 
MARTINS, Sueli Terezinha Ferreira. Psicologia social e processo grupal: A coerência entre fazer, pensar e sentir em Sílvia Lane. Psicologia \& Sociedade, 19. Edição Especial 2, 2007. P. 76-80.

MENEZES, Ebenezer Takuno de; SANTOS, Thais Helena dos. Verbete temas transversais. Dicionário interativo da educação brasileira - Educabrasil. São Paulo: Midiamix, 2001. Disponível em: <http://www.educabrasil.com.br/temas-transversais/> Acesso em 15 de março de 2017.

MORAES, Maria Cândida. Ecologia dos saberes: complexidade, transdisciplinaridade e educação. São Paulo: Antakarana/WHH - Willis Harman House, 2008.

PRADO, Maria Elisabete Brisola Britto. Pedagogia de projetos: fundamentos e implicações. In: ALMEIDA, Maria Elizabeth Biancocini de; MORAN, José Manuel (Org.). Integração das tecnologias na educação. Brasília: Ministério da Educação/SEED/TV Escola/Salto para o Furuto, 2005. Cap. 1. Artigo 1.1, p.12-17. Disponível em: http://www.tevbrasil.com.br. Acesso em: 03 de fevereiro de 2017.

SEVERINO, Antônio Joaquim. Metodologia do trabalho científico. São Paulo: Cortez, 2007. SILVA, Luciana Pereira da; TAVARES, Helenice Maria. Pedagogia de projetos: inovação no campo educacional. Revista da Católica. Uberlândia: v.2, n. 3, 2010. Disponível em: http://catolicaonline.com.br/revistadacatolica2/artigosv2n3/16-Pedagogia.pdf, acesso em: 12 de setembro de 2016.

TORRES, Patricia Lupion. Redes e conexões para compor os liames do conhecimento. In: Complexidade: redes e conexões do ser sustentável. Curitiba: SENAR, 2014. p. 15-31.

TORRES, Patrícia Lupion; BOCHNIAK, Regina. Educação e profissionalização para micro e pequenos empresários rurais em desvantagens sociais e de regiões menos favorecidas: Escola Aberta. Curitiba: Serviço nacional de Aprendizagem Rural - SENAR, 2000.

TORRES, Patrícia Lupion; IRALA, Esrom. Aprendizagem colaborativa: teoria e prática. In: Complexidade: redes e conexões na produção do conhecimento. Coleção Agrinho, Curitiba: SENAR, 2014. p. 61-94.

VEIGA, Ilma Passos Alencastro. Et. All. Ensino e avaliação: uma relação intrínseca à organização do trabalho pedagógico. In: Didática: o ensino e suas relações. Campinas: SP, Papirus, 1996. P. 149-183.

VEIGA, Ilma Passos Alencastro. Et. All. Perspectivas para reflexão em torno do projeto político-pedagógico. In: Escola: espaço do projeto político-pedagógico. Campinas: SP, Papirus, 1998. P. 9-32.

VEIGA, Ilma Passos Alencastro. A aventura de formar professores. Campinas: SP, Papirus, 2009.

VEIGA, Ilma Passos Alencastro. Formação de professores para a educação superior e a diversidade da docência. Revista Diálogo Educacional. Curitiba: v. 14, n. 42, p. 327-342, maio/ago. $2014 . \quad$ Disponível em: https://periodicos.pucpr.br/index.php/dialogoeducacional/article/view/6515. 
VENTURA, Paulo Cezar Santos. Por uma pedagogia de projetos: uma síntese introdutória. Educação Tecnológica. Belo Horizonte: v.7, n.1. jan./jun. 2002. Disponível em http://www.tecnologiadeprojetos.com.br/banco_objetos/\%7B6CC31958-0A79-4D36-8DADDC0D31DEE25C\%7D_Artigo\%20Paulo\%20Ventura\%20-

\%20Por\%20uma\%20Pedagogia\%20de\%20Projetos.pdf, acesso em 12 de janeiro de 2017.

ZABALA, Antoni. Enfoque globalizador e pensamento complexo: uma proposta para o currículo escolar. Porto Alegre: Artemd, 2002.

Artigo Recebido: 27 de março de 2021.

Artigo Aceito: 16 de maio de 2021. 